DOI: 10.14451/1.173.27

\title{
АНАЛИЗ ТЕОРИЙ РАСПРЕДЕЛЕНИЯ РАЗЛИЧНЫХ ЭКОНОМИЧЕСКИХ ШКОЛ
}

\author{
(c) 2019 Хаустова Карина Владимировна \\ аспирантка, Департамент экономической теории \\ Финансовый университет при Правительстве Российской Федерации, Россия, Москва \\ E-mail: khaustova.karina@mail.ru
}

Для любой экономической системы проблема экономического роста (фаза производства) и дальнейшего распределения и перераспределения выгод и благ от этого роста (самостоятельные фазы воспроизводства) актуальна и имеет ярко выраженную не только теоретико-методическую значимость, но и практическую, так как определяет уровень благосостояния и качества жизни населения.

В данной работе объектом исследования выступают экономические отношения в обществе, которые складываются на всех этапах создания общественного продукта, а предметом - эволюция взглядов на сами теории распределения.

Ключевые слова: Экономическая теория, распределение, перераспределение доходов, экономические школы, социальная политика, классическая школа, маржиналисты, социальные теории.

Под термином «распределение» в экономике понимается процесс разделения благ между субъектами экономических отношений. Первая стадия распределения созданного общественного продукта (первичное распределение) осуществляется на основе реализации прав собственности и разделения труда. Вторая стадия распределения (перераспределение) общественного продукта происходит при перераспределении доходов (передаче денег) или иных благ от одних хозяйствующих субъектов экономической системы к другим с помощью ряда социальных механизмов, к которым можно отнести: механизмы социальной поддержки государства (трансферты - пенсии, стипендии, пособия), фискальную политику (налогообложение), денежно-кредитную политику, благотворительность, земельное право, семейное право. Под категориями «распределение» и «перераспределение выгод» подразумевается не только распределение доходов, но и доступ к различным благам.

В рамках различных экономических школ существуют теории распределения доходов, однако они отражают только отдельные аспекты исследуемой проблематики, даже сама категория «доходы» стала использоваться относительно недавно, ранее использовалась такая экономическая категория, как богатство.

Несмотря на то, что проблема распределения практически не рассматривалась экономическими школами отдельно и в отрыве от смеж- ных основополагающих экономических теорий, она считалась одной из важнейших. Так, Давид Рикардо в своем труде 1817 года «Начала политической экономии и налогового обложения» писал: «Определить законы, которые управляют распределением,- главная задача политической экономии» [3].

Из всех тех экономических школ, которые были рассмотрены в предыдущем параграфе, можно выделить три основных направления, по которым шла разработка теорий распределения: классическая школа, маржиналисты, социальные теории распределения.

Термин «распределение» широко использовался в экономической науке еще в XVIII веке физиократами, но появление теории распределения как самостоятельной экономической категории можно отнести к XVIII веку и зарождению классической экономической школы.

Крупнейший представитель классической школы Адам Смит в своем труде 1776 года «Исследование о природе и причинах богатства народов» [4] рассматривал не только теорию стоимости, накопления капитала, экономическую историю стран западной Европы, государственные финансы и политику, но и теорию распределения доходов, которая рассматривалась с точки зрения образования различных видов дохода и форм их дальнейшего распределения (присвоения) между группами населения (классами).

Согласно концепции классической экономической школы, теория распределения тесно 
связана с теорией стоимости, ведь стоимость любого продукта состоит из заработной платы, земельной ренты и прибыли, которые являются первоначальными источниками дохода. Этот первичный доход в свою очередь распределяется между тремя основными классами: капиталистами (получающими прибыль), землевладельцами (получающими ренту) и наемными работниками (получающими заработную плату). Доходы остальных групп населения являются вторичными, так как их источником являются перераспределенные первичные доходы. По мнению ученого, с развитием общества и экономических отношений доля ренты и процента будет уменьшаться в общем объеме произведенного продукта, хотя доходы будут возрастать.

Причем А.Смит впервые рассмотрел проблему функционального распределения доходов в динамике и на долгосрочный период. Согласно хрестоматийному примеру Смита, в первобытном обществе земля никому не принадлежала и не являлась экономическим благом, также как и капитал, которого совсем не было, а вся стоимость продукта (например, пойманного на охоте бобра или оленя) сводилась к труду, который был затрачен на его производство (охоту и поимку). То есть на примитивном и первоначальном уровне развития общества распределения как такового не было, все забирал собственник труда как фактора производства. С развитием общества в создании общественного продукта помимо труда начинают участвовать другие факторы производства, т.е. появляются рента и процент. И чем больше доля ренты и процента в общем продукте страны, тем больше доля непроизводительных работников.

Еще один представитель классической школы, последователь и одновременно оппонент А. Смита - английский экономист Давид Рикардо один из первых поставил проблемы распределения в центр своих исследований. Он также как и Смит выделял три основных класса (владельцы земли, собственники капитала, рабочие) и три основных вида доходов (рента, прибыль, заработная плата), но дополнил трудовую теорию стоимости таким фактором, как затраты на средства производства. Он писал, что «на стоимость товаров влияет не только труд, применяемый непосредственно к ним, но и труд, затраченный на орудия, инструменты и здания, способствующие этому труду» [3]. Однако Д. Рикардо интересовал в большей степени не вопрос формирования стоимости товара, а законы распределения доходов в обществе. В основу этих распределительных процессов он закладывал классовые отношения, поскольку считал, что рост доходов капиталистов непременно ведет к снижению заработной платы рабочих и видел в этом обратную закономерную связь. Анализируя процессы распределения прибыли, ренты, процента и заработной платы между различными классами, он вывел свой «естественный» закон распределения дохода, согласно которому главенствующее значение в функциональном распределении играет цена хлеба (того, что получается с поверхности земли путем соединения труда, машин и капитала и делится между тремя классами общества в различных пропорциях, которые зависят от стадии развития общества). Хлеб - это основной продукт потребления и его цена определяет совокупную стоимость средств существования рабочих и, соответственно, их заработную плату. Доход капиталиста - это разница, которая остается после вычета из совокупного дохода ренты (ее величина определяется качеством и плодородностью земли) и заработной платы (величина которой должна поддерживать трудоспособность). Согласно Рикардо, естественная тенденции распределения заключается в том, что в долгосрочной перспективе уровень зарплаты не будет существенно изменяться, доля ренты должна расти, а процент на капитал, наоборот, снижаться. Взгляды Рикардо отличались либеральностью, он придерживался экономической концепции, не допускающей государственного вмешательства в экономику и предполагающей свободную торговлю и конкуренцию.

Существенный и оригинальный вклад в развитие теорий распределения внес один из последних представителей классической английской политэкономии Джон Стюарт Милль (1806-1873 гг.), который в своей работе «Основы политической экономии» [5] впервые указал на институциональные аспекты распределения доходов - законы прав собственности и наследования, систему земельной аренды. Он ввел различия между «законами производства, которые относятся к истинам естественного порядка» - например, законам физики, и законами «распределения богатства, которым занимаются исключительно человеческие институты». Такими институтами и главными факторами, влияющими на раздел продукта, он считал конкуренцию и обычаи. 
Маржиналистские теории распределения. Маржиналисты исследовали распределение с точки зрения максимального удовлетворения субъектов экономики (потребителей), учение их заключалось в поиске условий, при которых произведенный общественный продукт распределялся бы наиболее эффективно и с оптимальным результатом между конкурирующими направлениями использования. Если каждая единица делимого продукта (услуги) распределена так, что выгода перемещения ее к одному из способов будет в точности равна потерям изза отвлечения ее от другого способа, то принцип максимизации, состоящий из уравнивания предельных значений, работает.

Также представители маржинализма утверждали, что в каждом случае проблема распределения имеет максимизирующее решение тогда, когда передача единицы делимой величины одному единственному способу употребления подвержена закону убывающей отдачи. Впервые теорию распределения на основе идеи предельной производительности в достаточно подробной форме высказал немецкий экономист и предшественник маржинализма И. Г. фон Тюнен (1783-1850 гг.) в своем труде «Изолированное государство» [7]. Пользуясь методами дифференциального исчисления, И. Г. фон Тюнен вывел формулу, в которой заработная плата сельскохозяйственного рабочего равнялась $\sqrt{\mathrm{a} * \rho}$ где а - необходимый прожиточный минимум; p - предельный продукт предельного участка. Следовательно, остальное шло на долю капитала (потому что весь продукт делится только между трудом и капиталом, ведь предельный участок не дает ренты).

Из родоначальников маржинализма рассматривали в том или ином ракурсе проблемы распределения К. Менгер, его ученики Е. Бем-Баверк и Ф. Визер. К. Менгер отвергал характерную для классической школы идею деления факторов производства на землю, труд и капитал, так как считал, что все факторы и ресурсы играют по существу одинаковую роль, а ценность этих факторов (К. Менгер использовал термин «блага высшего порядка») определяется на основе ценности создаваемых ими потребительских «благ низших порядков». Вклад каждого блага высшего порядка в конечный произведенный общественный продукт определяется тем, насколько уменьшается этот общий произведенный продукт из-за отсутствия или ограничен- ного и небольшого количества данного блага в производственном процессе. Характер распределения обусловливается принципом вменения, который гласит, что совокупный общественный продукт распределяется между всеми участвующими в производстве факторами в пропорциях, устанавливающимися в процессе вменения. Более современны вариант этой теоремы распределения можно сформулировать так: если доходы пропорциональны размерам производимого продукта и оплата каждого из факторов равна производимому им предельному продукту, то общая сумма таких выплат равна производимому продукту. При этом предполагается совершенная конкуренция, которая не существует в реальном мире.

Теорию распределения также разрабатывали Е. Бем-Баверк и Ф. Визер, основное ее положение - при наличии различных форм использования благо должно распределяться таким образом, чтобы достигалась максимальная предельная полезность. Согласно учению маржинализма, смысл и содержание хозяйственно-экономической деятельности состоит в том, чтобы минимизировать издержки и максимизировать полезность, цены, производство, доход, используя для этого математические методы дифференциально исчисления.

Теорию распределения А. Маршалла нельзя назвать самостоятельной, она скорее была дополнением к теории стоимости. В ней были рассмотрены условия спроса и предложения, которые оказывают одинаковое влияние на цену каждого фактора производства (и на заработную плату). Ни спрос, ни предложение не могут играть главную роль, так же как на нее не может претендовать каждая из опор арки или ни одно из пары лезвий ножниц. Заработная плата имеет тенденцию быть равной чистому продукту труда, а предельная производительность труда регулирует цену спроса на него. Задача теории распределения - обнаружить силы, определяющие предложение и спрос на каждый фактор.

Важный вклад в маржиналистскую теорию распределения внес Дж.Б. Кларк. Хотя многие положения этой теории были высказаны и до Кларка, именно он придал ей законченный вид. Эта теория изложена в труде «Распределение богатства» [8]. Дж. Кларк, так же как и К. Менгер, отрицал существование значительных различий между разными факторами производства и их влиянием на цену. Для определения вкла- 
да каждого из факторов в конечный продукт Кларк предлагал учитывать прирост продукта, который достигается благодаря использованию дополнительной единицы данного фактора при фиксированных значениях других факторов. Он как о естественном законе говорит, что каждый фактор в конце концов получает только то, что он «заслуживает», а заслуживает он столько, сколько произвел, а сколько он произвел зависит от того, какая у него предельная производительность.

Английский экономист и теолог Филипп Уикстид (1844-1927 гг.) в 1894 г. опубликовал книгу «Эссе о согласовании законов распределения», выдвинув в ней свое математическое обоснование проблемы распределения и анализ экономической системы. Чарльз Кобб и Пол Дуглас в работе «Теория производства» говорят, что первая формулировка функции Кобба - Дугласа была сделана именно в этой работе Уикстида. В существенно переработанном виде он изложил теорию распределения в своем фундаментальном труде «Здравый смысл политической экономии» в 1910 г. Он впервые математически показал, что в условиях равновесия сумма доходов каждого фактора, определяемая его предельной производительностью, в точности совпадает c денежной величиной совокупного продукта, производимого с их участием при условии линейной однородности производственной функции. Таким образом, не может идти и речи о каком-либо факторе, чья доля определяется «остаточным принципом» (т.е. которому достается все оставшееся после установленных выплат другим факторам). В экономической науке это утверждение получило название «проблемы исчерпаемости». Уикстид также отрицал какое бы то ни было деление факторов на группы, присоединяясь к тем, кто указывал на единообразие принципов ценообразования и распределения по всем, без исключения, используемым ресурcam.

Многие ученые так или иначе исследовали проблемы распределения, наиболее значительный вклад в данную область с точки зрения теории предельной производительности внесли также лидер лозанской школы маржинализма Л. Вальрас («Элементы чистой политической экономии», 1874) и его последователь В. Парето («Курс политической экономии», 1906), английские ученые Ф. Эджуорт и Д. Робертсон («Лекции об экономических принципах», 1957), основа- тель шведской школы К. Викселль («Ценность, капитал и рента», 1893), внесший в область экономических исследований элемент времени, американцы П. Дуглас («Существуют ли законы производства?», 1948), Дж. Стиглер («Теории производства и распределения», 1941) и другие.

В конце XIX - начале XX века впервые учеными было обращено внимание на то, что при изучении специфики отношений при процессе распределения нужно принимать во внимание не только теорию ценности, но и социальные аспекты, например, исследовать соотношение сил между классами (группами населения), между которыми происходит распределение общественного продукта. Сторонники социальных теорий распределения считают распределение обособленным и самостоятельным процессом, на которое большое влияние оказывают такие неэкономические факторы, как право, политика, обычаи.

Немецкого ученого Е.Дюринга (18331921 гг.) можно причислить к одним из первых представителей социальных теорий (в силу существенной разнородности этих теорий, нельзя назвать их школой). Социальная теория распределения Дюринга основана на несколько идеалистическом воззрении, которое состоит в том, что насилие является причиной неравенства, бедности и эксплуатации населения, а само распределение основывается на соотношении социальных сил классов, которые присваивают себе блага. Преобразование общества, по мнению Дюринга, не должно идти революционным путем, а решением социальных проблем общества является кооперирование мелких производителей.

Еще одним представителем социальных теорий распределения можно считать немецкого экономиста и юриста Рудольфа Штольцмана (1852-1930 гг.), создателя «социально-органического» метода («Цель народного хозяйства», 1909). По мнению Штольцмана, распределение - это социальная категория, вытекающая из общественной природы человека, из вечно меняющихся исторических законов общежития и совместной работы людей. Поэтому законы распределения являются «делом рук самого общества», то есть зависят только от воли людей.

По его мнению, при установлении пропорций распределения дохода между собственниками факторов производства решающее влияние оказывает социальная позиция. Это формиро- 
вание долей Штольцман называл «социальным наделением», а меру «социального наделения» определял не вкладом определенного класса в производство, а неким «социальным минимумом», необходимым для того, чтобы члены общества выполняли необходимые функции.

Социальный прожиточный минимум необходим не только рабочим, но и владельцам капитала, так как у них тоже есть некие общественные обязанности в системе народного хозяйства Таким образом, размер заработной платы определяется социальным прожиточным минимумом предельного рабочего, так же как и величина прибыли определяется социальным прожиточным минимумом предельного владельца капитала.

Достаточно близка как к теории распределения Штольцмана, так и к теории Дж. С. Милля, который утверждал, что «распределение богатства зависит от законов и обычаев общества. Правила, которые определяют распределение богатства, таковы, какими их делают мнения и желания правящей части общества, и весьма различны в разные века в разных странах», социальная концепция распределения, которую развивал наш соотечественник М.И. Туган-Барановский (1865-1919 гг.) в своих трудах «Основы политической экономии» (1911) и «Социальная теория распределения» (1913). Туган-Барановский отмечал, что политическая экономия рассматривает проблему распределения «как проблему об отношениях зависимости между доходами тех общественных классов, которые связаны между собой условиями капиталистического производства и обмена» [9].

Как и другие представители социальных теорий, Туган-Барановский не соглашался с представителями теории предельной полезности (Дж. Кларком, Бем-Баверком) и отмечал, что движение цен определяется исключительно индивидуалистическим подходом, в то время как законы распределения можно определить только тогда, когда распределение рассматривается как социальный феномен, «предполагающий совместное действие многочисленных общественных групп». Туган-Барановский считал, что распределение - это историческая категория социального хозяйства и возможно оно только в обществе, обладающим определенной «исторической структурой», а сущность феномена распределения - это неравенство, ведь участники процесса распределения не равны в социальном отношении. Если при товарном обмене роли продавца и покупателя могут меняться, то в распределении они не могут поменять принадлежность к различным экономическим классам.

Все рассмотренные теории распределения как доходов, так и общественных благ, не предполагают равномерного распределения среди населения и неразрывно связаны с понятиями неравенства и бедности.

На снижение того неравенства, которое возникает на уровне первичного распределения, направлены социальные меры государства по перераспределению доходов (вторичное распределение).

Перераспределение доходов осуществляется государством с помощью социальной, фискальной, денежно-кредитной, бюджетной политики. Перераспределение осуществляется как прямыми, так и косвенными методами, к которым относятся: трансфертные платежи - обязательные выплаты населению за счет бюджетных средств на безвозмездной основе (пенсии, стипендии, компенсации, пособия и др.); регулирование цен на социально важную продукцию; индексацию фиксированных доходов и трансфертных платежей на уровень инфляции; минимальный размер оплаты труда (выше прожиточного минимума); прогрессивное налогообложение (с ростом номинального дохода увеличивается и налоговая ставка).

В экономической теории можно выделить два подхода по отношению к мерам социальной поддержки государства: социальный и рыночный.

Первый подход определяет, что государство (общество) должно гарантировать каждому гражданину минимальные доходы, не позволяющие ему опуститься ниже черты бедности. При этом такая помощь должна быть оказана по критериям нуждаемости и адресности, в то же время такие расходы государства должны быть под силу государственному бюджету и не создавать инфляционного давления, которое в свою очередь может ухудшить положение малоимущих слоев населения.

Второй подход основан на том, что задача государства дать возможность каждому члену общества возможность вести достойный образ жизни, создавать условия для повышения уровня и качества жизни, а не только гарантировать минимальный доход. 


\section{Библиографический список}

1. Анисимова, Г.В. Проблемы социально-экономической дифференциации в российском обществе. // Г.В. Анисимова. М., 2008.- 136 с.

2. Бем-Баверк, Ойген. Основы теории ценности хозяйственных благ // Избранные труды о ценности, проценте и капитале/ Ойген фон Бём-Баверк.-М.: Эксмо, 2009.- С. 49-246. - 912 с.

3. Рикардо Д. Начала политической экономии и налогового обложения // Антология экономической классики. М., 1993. С. 315.

4. Смит, А. Исследование о природе и причинах богатства народов. Т. 1,2. -М, 1962.

5. Милль, Дж. С. Основы политической экономии. В 3 т. М.: Прогресс, 1980-1981; т. I - 495 е.; т. II - 480 е.; т. III -447 c.

6. Рассадина М.Н. Дифференциация доходов населения: проблемы и пути решения // NovaInfo.Ru - № 56, 2016 г.

7. Тюнен И. Изолированное государство.-М.: Экономическая жизнь, 1926.

8. Кларк, Дж. Б. Распределение богатства. / Дж.Б. Кларк- М.: Гелиос АРВ, 2000.-368с.

9. Туган-Барановский, М.И. Социальная теория распределения // Солнцев С.И., Туган-Барановский М.И., Билимович Л.Д. Социальная теория распределения / под ред. М.Г. Покидченко, Е.Н. Калмычковой. М.: Наука, 2009. С. 307-308.

10. Kuznets $S$. Economic growth and income inequality // American Economic Review.1955. Vol. 45. No 1. P. 1-28. 